\title{
"The Phenomenon of Trade-Based Money Laundering in Bangladesh" - A Critical Review
}

\author{
Md Monzur Morshed, Taiabur Rahman \\ Department of Development Studies \\ University of Dhaka \\ Dhaka, Bangladesh \\ \{m.monzur, taiabur.rahman\}@gmail.com
}

\begin{abstract}
Bangladesh is one of the victims of financial crime like money laundering. Bangladesh's gross domestic product (GDP) has risen to 329.12 billion dollars in recent years and is steadily expanding. According to BASEL AML Index data (2020), Bangladesh's current AML score is 5.88. It stands in 38 rankings among 141 countries where Afghanistan ranks in the number one position, scoring 8.16, and Estonia ranks in 141 places with a score of 2.36. To fight financial crime like money laundering, The Central Bank of Bangladesh has taken necessary steps to be in line with FATF Status. In this connection, TradeBased Money Laundering is a type of money laundering that shall closely monitor. Under-invoicing and over-invoicing are regularly practiced by the importers and exporters while declaring false prices of the goods. The remaining capital flies through "Hundi" and other media like Bitcoin or cryptocurrency platforms and uses offshore tax havens to hide the money. Though ML / TBML is a common problem over the entire world, in comparison to others, Bangladesh's progress is not significant, and not enough academic research is being published, which creates a considerable gap between the Government agencies and academia. This study attempts to break the ice between government agencies and academia. Still, more in-depth research shall be needed to combat Money Laundering (ML) or Trade-Based Money Laundering (TBML).
\end{abstract}

\section{Introduction}

In Bangladesh's developing economy, money laundering and terrorism financing have become a severe threat. Trade-based money laundering is a method of concealing criminally obtained funds through the use of trade. According to the BFIU, even though most capital flights originate in China and India, Bangladesh was the first country to announce the guidelines for the banks (The New Age: December 12, 2019). A special committee led by a deputy general manager of Bangladesh Bank has been constituted to track down and examine money laundering. After evaluating the relevant trade data, the committee would visit the related bank in the event of an occurrence (The Daily Star: December 12, 2019). TBML occurs under the disguise of trade such as import-export while manipulating goods \& products prices, which in- 
volves actors in different layers. By only imposing strict policies in the banks, it may not be possible to combat TBML.

As international trade expands, TBML is becoming an increasing worry for the banking industry. According to BASEL AML Index, Bangladesh's current ranking is 38 among 141 countries having a score of 5.88. Since Bangladesh's economy depends entirely on export-import, there is a significant gap in financial intelligence and a lack of human resources to fight money laundering. In this study, the key focus is to identify the gaps in banking, develop a comprehensive framework to combat TBML, and offer a set of recommendations.

In a study (2006), Financial Action Task Force (FATF) recognized TBML is one of the most common strategies criminal groups and terrorist financiers use to move money and conceal its origins while integrating into the formal economy. It involves a multi-level of stakeholders, including banks, indentors, shipping intermediaries, forwarding agents, consignees, notifying parties, etc. According to Global Financial Integrity, Bangladesh is one of the most vulnerable countries to trade-based money laundering (TBML), which poses a severe threat to the country's economy. The possible reasons behind the TBML could be lack of awareness among bankers, lack of coordination among Government agencies and banks, lack of human resources, and not adopting proper tools and techniques. Thus, it has become essential to conduct a critical review study on Trade-based Money Laundering in Bangladesh. We hope that this study will play a pivotal role in identifying loopholes and develop a comprehensive framework that will increase the capacity of local human resources and strengthening the AML units of the banks and law enforcement agencies to combat TBML in Bangladesh.

\subsection{Trade-Based Money Laundering Techniques}

In conventional money laundering involving the transfers of money, criminals seek to apply various techniques such as placement, layering, and integration. In TBML, criminals use the formal trading processes to transfer illegal money using traditional banking channels while involving multiple stakeholders. There are several methods are used to execute TBML, as given below (Cassara \& Poncy, 2015):

- Over-invoicing and under-invoicing and shipments of goods and services

- Multiple invoicing of goods and services

- Falsely declaration

- Short-shipping

- Over-shipping

- $\quad$ Phantom shipping (False documents to justify payment abroad)

To further identify the loopholes, we collected and studied Wolfsberg Group Correspondent Banking Due Diligence Questionnaire (CBDDQ) V1.2. Every public and private bank completed this questionnaire, and while browsing the internet, we gathered ten banks' assessment reports, as provided on the respective banks' websites. 
After interviewing two bank officials, it was understood that the traditional banking system could not fight trade-based money laundering even though most banks have full-filled anti-money laundering compliance using the Wolfsberg Group Correspondent Banking Due Diligence Questionnaire. Usually, every bank's branch has a designated official: Branch Anti-Money Laundering Compliance Officer (BAMLCO) who reports to the Chief Anti-Money Laundering Compliance Officer (CAMLCO) in the head office of the respective bank. To fight TBML, BAMCLOs usually follow the circular of Bangladesh Bank, Central Bank of Bangladesh (e.g., circular numbers 19, 24, 25 as published on BFIU's portal).

Generally, BAMLCOs follow the Bangladesh Bank's guidelines by conducting KYC (Know Your Customer), investigating LC-related documents, and looking for United Nation's sanction information against respective users/companies using the standard banking software platform. Since TBML occurs through manipulating goods price and quantity, which are the key factors, and banks do not have any control over it, there is no such platform where banks can consult on import-export issues.

\section{Money Laundering in Bangladesh Economy}

Money Laundering is a big issue for any country's economy regardless of its status. Over the years, money laundering crime has increased significantly in Bangladesh. According to the Global Financial Integrity (GFI), the total amount of Tk. 6,50,000 crore money was laundered from Bangladesh in the last ten years (Daily Sun, July 2018). According to Basel AML Index 2020 report, Bangladesh's rank is 38 among 141 countries as scored: 5.88 whereas Afghanistan rank is $1^{\text {st }}$ among 141 countries and Estonia rank is 141 having a score of 2.36.

According to Global Financial Integrity's most recent report, around 18\% of Bangladesh's total trade value mismatched with all the trading partners (The Financial Express: March 04, 2020).

\subsection{Invoice Fraud, Money Laundering and Current Scenario in Bangladesh}

Trade-based Money Laundering occurs by manipulating export/ import invoices through the over-and under-invoicing of goods and services. In this study, we interviewed several government officials of Bangladesh. According to one of the government officials from the Criminal Investigation Department (CID), over-invoicing occurs during the import process. For over-invoicing, usually heavy machinery \& equipment are the first choice for TBML. According to CID official website, a total of 153 money laundering cases have been filed and are being investigated, but no charge sheets have been filed in any of them. We learned that the Bangladesh Financial Intelligence Unit (BFIU) is the country's central intelligence agency during the interview. It is responsible for analyzing suspicious transactions, cash transactions, and information related to money laundering and terrorism financing received from reporting 
agencies and other sources. The Money Laundering Prevention Act of 2012 and the Anti-Terrorism Act of 2009, as amended in 2013, govern the BFIU. It is a technical unit that supports the respective government units to combat money laundering in Bangladesh by providing intelligence data. Since several government agencies like CID, CIID (Customs Intelligence \& Investigation Directorate), Anti-Corruption Commission, etc., handle money laundering cases. It is understood that bureaucracy plays a significant role. During the conversation with the CIID official, we learned that the CIID did file a total of 83 cases between 2016 and 2019 and was unable to collect any substantial data on those cases owing to their sensitivity.

\section{Literature Review}

Bangladesh is the fastest growing economy having a population of over 180 million. Her economy is heavily dependent on imports in comparison to export. In January of 2020, Bangladesh had a trade deficit of 135.70 BDT billion. To strengthen the economy, it has become essential to put a lot of monitoring to control TBML. To combat TBML, BFIU recommends a set of Laws, Rules, Regulations, and Guidelines (BFIU, 2019) such as Money Laundering Prevention Act, 2012; Money Laundering Prevention Rules, 2019; Anti-Terrorism Act, 2009; Anti-Terrorism Rules, 2013; Foreign Exchange Regulations Act, 1947; Customs Act, 1969; The Import and Export Control Act, 1950; Importers, Exporters and Indentors (Registration) Order, 1981; Value Added Tax Act, 1991; Import Policy Order and Export Policy in-force; Rules, Govt. SROs, Circulars, Circular letters, Guidelines, instructions issued by relevant authorities/regulators.

"Money laundering is one of the major factors that contributed to the rise in the country's trade deficit," says Ahsan H Mansur, Executive Director of Policy Research Institute (Dhaka Tribune, September 6th, 2018).

According to BFIU's new strategy to stop money laundering, all banks have been requested to fully cooperate with the Customs Intelligence and Investigation Department (CIID) to stop capital flight and take legal actions against the money launderers. The majority of money is laundered through fake export-import declarations: Capital flight equals the country's 36\% tax rate (Daily Asian Age, 12 December 2019). It is estimated that illicit financial outflow or money laundering from Bangladesh was ranging from $\$ 2.7$ billion to $\$ 5.9$ billion in 2015 and the amount drained out through over-invoicing in imports and under-invoicing in exports (New Age: Mar 04, 2020).

Bangladesh is currently working to improve its anti-money laundering and counterterrorist financing (AML/CFT) system. Bangladesh has ratified the United Nations Vienna Convention of 1988 and the United Nations Convention against Terrorist Financing and enacting anti-money laundering legislation that covers serious offenses and reporting suspicious transactions (Asia Pacific Group of Money Laundering, 2019). 
According to the report of the Daily Star, Bangladesh has risen 28 places in the Basel Institute on Governance's anti-money laundering and counter-terrorist financing (AML/CTF) ranking, which the Government would welcome. A total of 14 indicators relating to AML/CTF legislation, corruption, financial standards, political disclosure, and the rule of law are combined to create the index's overall risk score (The Daily Star, August 22, 2017).

According to the news report of The Financial Express, Bangladesh is now working to form an alliance with 12 nations for retrieving black money. (The Financial Express, November 05, 2020).

According to GFI statistics, an average amount of US\$7.53 billion is laundered each year from Bangladesh. (The Financial Express, July 29, 2020).

Many Bangladeshis are securing Canadian citizenship by depositing 150,000 Canadian dollars (The Financial Express, March 01, 2020) though there is no financial transaction data to the Government of Bangladesh or the Bangladesh Bank.

According to the Global Financial Integrity report, 'Illicit Financial Flows (IFFs) to and from Developing Countries', on an average, $\$ 6.16$ billion was laundered every year during 2014-17 (The Financial Express, June 30, 2020).

According to the report of the Financial Express, the Government of Bangladesh has begun implementing significant elements of a national strategy to combat money laundering and terror financing, mainly across the country (The Financial Express, September 23, 2020).

According to the report of the Daily Star, Bangladesh was the first country in South Asia to enact the Money Laundering Prevention Act in 2002, following the recommendations of the Financial Action Task Force (FATF), an intergovernmental body dedicated to combating money laundering (The Daily Star, Jul 2, 2020). On the other hand, experts have questioned the Government's efforts to put the suggestions into action (The Financial Express, July 02, 2020).

According to the report of the Daily Star, In a more recent analysis, GFI revealed that trade mis-invoicing resulted in USD 5.9 billion being stolen out of Bangladesh in 2015 (The Financial Express, July 02, 2020).

According to a new report of the Daily Star, Surprisingly, over 35\% of Bangladeshi banks experienced no financial crime from 2014 to 2016. (The Financial Express, December 03, 2016).

A developing economy like Bangladesh cannot afford the capital flight, which is predicted to cost between $\$ 6.0$ billion and $\$ 9.0$ billion each year, according to Global Financial Integrity (The Financial Express, August 17, 2019).

According to GFI estimates, illicit outflows from the country were $\$ 5.2$ billion in 2015, while inflows totaled \$2.8 billion (The Financial Express, June 01, 2019). 


\section{Research Methodology}

This study followed a qualitative research approach. The aim was to find out the critical factors associated with trade-based money laundering and to identify the gaps in the existing environment of financial intelligence units of banks and related agencies. To learn the current setting of the banking and financial industry, open-ended interviews were conducted by interviewing bankers, law enforcement agencies, lawyers, and officials of the Government of Bangladesh. Besides interviews, the study also includes literature review, studying official documents, and daily newspapers.

\subsection{Data Source}

For this study, several professionals were interviewed, including bankers, government officials, bankers, and lawyers. By interviewing them, a significant amount of information was collected and highlighted throughout this study. Secondly, we requested NBR and CIID to provide us with the official data on TBML and the cases filed for money laundering. However, they said that such data $\&$ information could not be released due to their policy. Therefore, for data, this study heavily relied on secondary data sources as published on the web, news report, GFI report, etc.

\subsection{Targeted Population}

Our target populations were government officials, law enforcement agencies, bankers, lawyers, and business professionals to conduct this research study.

\subsection{Research Tools: Purposive Sampling Technique, Snowball \& KII}

To conduct this research, we did use Purposive sampling, Snowball sampling, and Key Informant Interviews techniques. In the beginning, we struggled a lot because there are not enough research materials on TBML from the Bangladesh context. After doing the background study and existing literature reviews, we initially interviewed an official of Bangladesh Police who works in CID. During the interview, the official helped us with valuable information and offered some recommendations. Based on the advice, we did communicate with BAMLCOs of two banks (private \& public). Then, the BAMLCOs informed us that the Bangladesh Bank plays a significant role in combatting money laundering issues. With such a clue, we set a meeting with a senior official of the Bangladesh Bank. Based on the feedback of the Bangladesh Bank official, then we made contact with the officials of NBR, CIID (NBR), and a senior legal consultant. 


\subsection{Data Analysis and Interpretation}

We analyzed Money Laundering Data of the SAARC countries from the year 20082012. Among the eight SAARC countries, the below graph depicts that India, Bangladesh, Pakistan, and Sri Lanka were having serious capital outflows due to money laundering. According to the BASEL AML Index (2020), now India ranking is 70 (score: 5.15), Bangladesh ranking 38 (score: 5.88), Pakistan ranking is 28 (score: 6.3), Sri-Lanka ranking is 23 (score: 6.52), Afghanistan ranking is 1 (score: 8.16). India has improved in AML compliance, whereas the remaining South Asian countries are struggling, including Bangladesh.

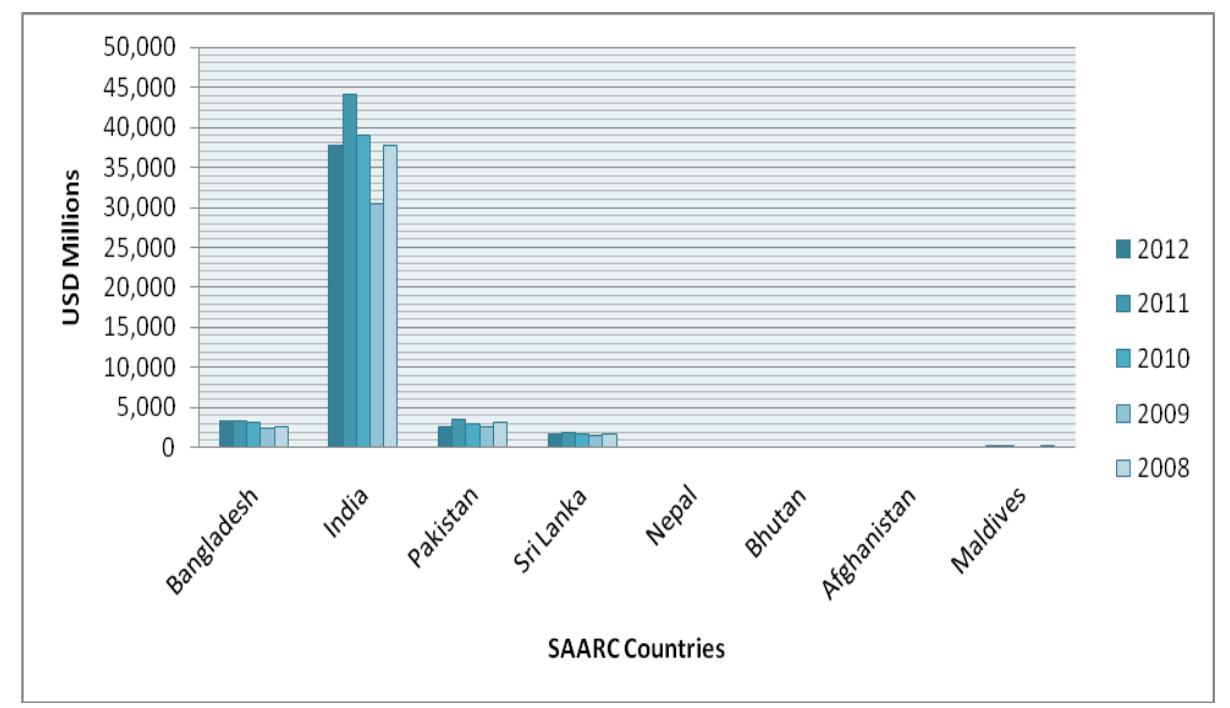

Figure 1: Money Laundering Data Analysis of the SAARC Countries (Year 2008-12)

\section{Interview Section}

To conduct this study on Trade-based Money Laundering, we interviewed several government officials from law enforcement agencies, the banking sector, and professional legal advisors. To ensure their privacy and research protocols, we are refraining from mentioning their details. Therefore, we categorized each of the interviewees as case 1 , case 2 , case 3 , etc., in such order. 


\subsection{Case 1: Interview of a Bangladesh Police Official}

The interview session was started by interviewing an official of Bangladesh Police who is currently working under the Economic Crime Squad. During the interview session, he briefly talked about the basics of money laundering and his experiences in fighting money laundering issues. According to the official, CID has to collaborate with several Government units such as NBR, CIID, BFIU, Anti-Corruption Commission, and banks both public and private-owned. Usually, CID does not proactively take any initiatives to fight money laundering; instead, Economic Crime Squad works as a helping hand of BFIU and other units of the Bangladesh Government in investigating financial crimes and filing cases in the courts. We observed that the official had to interact with a private Bank official having the designation of BAMLCO (Branch Anti Money Laundering Compliance Officer). The officer also mentioned that most money laundering cases were related to fraudulent import bills/invoices. The official also informed that the Forensic Training Institute (FTI) of the Criminal Investigation Department (CID) offers training to combat money laundering. The participants are senior-level police officers, learned judges, Anti-corruption officials, Bangladesh Bank officials, PBI, and mid-level police officers.

\subsection{Case 2: Interview of a BAMLCO of a Private Bank}

The interview session was started by interviewing a private bank official having the designation of BAMLCO (Branch Anti Money Laundering Compliance Officer). During the interview session, the official was reluctant to talk frankly and requested official permission from the respective bank's head office. However, we asked him to assist us by providing minimal information to continue the research work. Finally, he agreed to support us. After that, we did ask him about his work process, and he informed us that as a BAMLCO, he does the KYC (Know Your Customer) when a client requests to open an LC account in the respective branch. Then the official checks whether the individual client/ company has any sanction by cross-checking the UN Sanction Knowledge base/ database. Furthermore, he mentioned that all the banks strictly follow the circulars issued by the BFIU, Bangladesh Bank (especially circulars 19 and 25 as published on BB's BFIU Web Portal).

\subsection{Case 3: Interview of a BAMLCO of a Public Bank}

The interview session was started by interviewing a public bank official having the designation of BAMLCO (Branch Anti Money Laundering Compliance Officer), which is equivalent to the position of Senior Principal Officer. During the interview session, we asked her about the entire work process. She said that as a BAMLCO, initially, she does check three things of a new client which are KYC (Know Your Customer), TP (Transaction Profile), and Risk Assessment. Then the BAMLCO also 
cross with the database of the CIB (Credit Information Bureau), which is under the jurisdiction of the Bangladesh Bank.

\subsection{Case 4: Interview of a senior-level official of the Bangladesh Bank}

The interview session was started by interviewing a Bangladesh Bank's senior-level official. According to the official, BFIU is a national financial intelligence unit that helps relevant government agencies (CID, NBR, Anti-Corruption, CIID, etc.) and performs the secretarial job for National Coordination Committee (NCC) on AML/CFT, Working Committee (WC) and take necessary steps to implement the decisions taken in the NCC, WC. According to him, Bangladesh Bank issues circulars and provides essential guidelines to all the banks and financial institutes. The official said that Bangladesh Bank had taken necessary steps to fight money laundering crimes and closely working with the Financial Action Task Force (FATF). However, he also mentioned the capacity building issue, but the Bangladesh Government has shown a positive attitude to fight money laundering crimes.

\subsection{Case 5: Interview of an Official of NBR}

The interview session was started by interviewing an NBR (National Board of Revenue) official who was kind enough to discuss various issues on Trade-based Money Laundering. According to him, NBR runs a software system named ASYCUDA (Automated System for Customs Data), which holds all the import and export data of Bangladesh's economy. Finally, he mentioned that CIID (Customs Intelligence \& Investigation Directorate) deals with the issues related to Trade-based Money Laundering (TBML) and introduced us to an official of CIID, NBR.

\subsection{Case 6: Interview of an Official of CIID (NBR)}

The interview session was started by interviewing a CIID official. The official mentioned that from 2016-2019, the CIID has filed 83 cases. However, we were unable to collect any significant data on those cases due to their sensitivity. He also informed that Trade-based Money Laundering (TBML) usually occurs by manipulating import \& export invoices, also known as over-invoicing and under-invoicing techniques. According to him, there is a tendency among few importers to make a false declaration to the customs by which TBML also takes place. He also informed that the authority had taken necessary steps to fight money laundering crime, especially TBML, by automation and procurement of sophisticated scanning machines, hardware, smart devices, etc.

\subsection{Case 7: Interview of A senior-level legal consultant}

The interview session was started by interviewing a legal consultant who is also an Anti-Money Laundering expert. Since he is a legal professional, we asked him about 
the cases filed for money laundering crimes and their future in court. According to him, in court, most of the time, the claims remain unsettled due to the technical ground. He also mentioned that to fight money laundering crimes, there is no alternative to good governance, political will, the rule of law, transparency, decentralization, and neutral bureaucracy.

\section{Proposed Anti-TBML Framework}

According to BFIU's new strategy to combat trade-based money laundering, all banks shall communicate with CIID regarding import/ export-related matters. However, based on the research findings, several government units should not be left alone. Every stakeholder who influences trade, law enforcement agency, ministry, business leaders, journalists, academics, etc., shall work under one umbrella. Without such collaborative afford, combating trade-based money laundering or, more broadly, "money laundering" cannot be tackled! Based on the interviews, we learned that the traditional banking sector could not fight TBML. In this section, we focus on a proposed comprehensive framework to combat TBML.

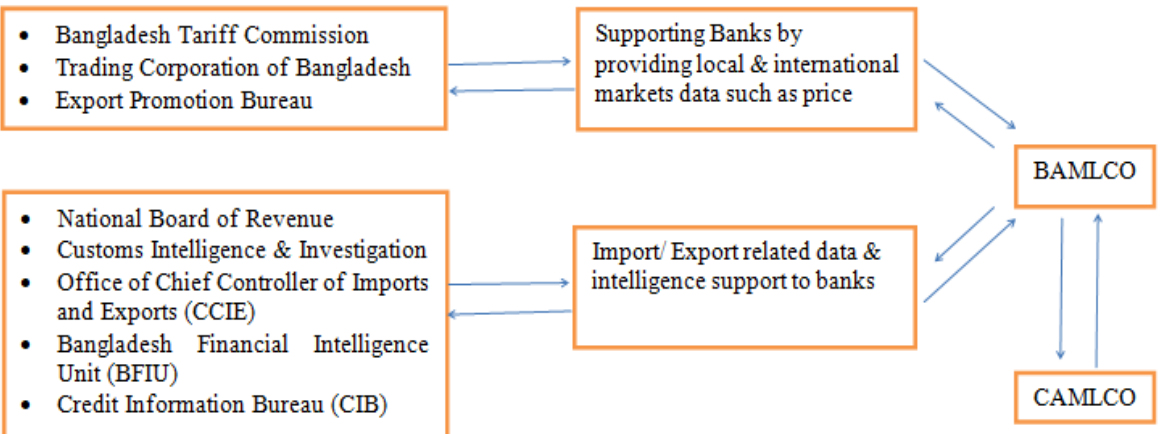

Figure 2: Comprehensive framework to combat Trade-based Money Laundering

\section{Study findings}

Based on the study, we can say that the traditional banking system in Bangladesh cannot combat Trade-based Money Laundering. Though banks followed the Wolfsberg Group Correspondent Banking Due Diligence Questionnaire (CBDDQ) V1.2 to assess AML compliance, but there is still enough space to work in this area. With the rapid expansion of digitalization, capacity building, the collaboration between the Government agencies, Central Bank, Law Enforcement agencies, academia, etc., we can strengthen the fight against TBML or any financial crimes.

To battle money laundering, several Government agencies of Bangladesh work, but there is an inbuilt bureaucracy within the institutions that hinders the investigation and legal procedures as the definition of money laundering is still not fully understood. Money laundering can occur within the country, whereas Trade-based Money 
Laundering occurs by manipulating the price of goods while importing or exporting to foreign countries.

Since there is no independent unit of the Bangladesh Government to battle money laundering or financial crimes, it always becomes a lengthy process to bring the criminals under justice. Using the legal loopholes and political influence, they get away quickly. So far, 153 money laundering lawsuits have been filed and investigated by CID (Bangladesh Police), but no charge sheets have been filed yet. The CIID (NBR) filed 83 lawsuits between 2016 and 2019; however, there has been no progress on those cases so far and formally requested to avail the relevant data, which was somehow unsuccessful.

In Bangladesh, most banks are now going through digitalization. However, a centralized system shall be controlled and monitored by the special units or an independent commission to track and trace export and import-based trade data.

The most important finding is the "lack of skilled human resources" in the respective Government agencies to combat TBML. There is also a considerable gap between government agencies and academia, but collaboration between the relevant stakeholders can be increased. Universities can organize workshops, seminars and offer standard courses to empower the officials and actors battling money laundering.

Finally, another most crucial finding is data availability. It isn't easy to visualize the complete scenario of the ML/TBML without access to real-time data.

\section{Recommendations}

- A joint consortium can be formed with the Government, Law Enforcement Agencies, Bangladesh Bank, and units like BFIU and CIB, Public \& Private Banks, NGOs, Financial Institutions, Civil Society and Think Tanks, Academia, etc.

- An investment-friendly environment so that big companies and investors become interested in investing in local industries.

- Bangladesh Government may declare a region-specific tax heaven idea so that poorer regions experience more business intervention which will ultimately improve the overall national economy and less risk for money laundering.

- A special unit or commission can be formed to combat Trade-based Money Laundering, which is run by specially trained officials who are experts in digitalization, data science, research, banking, trade, policy, and legal areas.

\section{Conclusions}

Money laundering through trade is a problem that affects all countries, not only Bangladesh. It has become essential to strengthen the financial monitoring forces, ensure transparency and good governance among the public and private intuitions to combat Trade-based Money Laundering and any corruption to ensure social justice and inclusiveness. 
Based on the feedback of the seven KII, we can conclude that there are many scopes to improve the capacity of the actors involved to combat TBML while applying necessary policy formulas. According to the BASEL AML Index, Bangladesh ranks in 38 positions whereas India ranks in 70 and other SAARC countries such as Afghanistan, Pakistan ranks in 1 and 28, respectively.

In Bangladesh, bureaucracy plays a crucial role in all aspects to combat TBML. Since several actors are involved in combating money laundering, it is needed to establish a unique and independent commission; otherwise, cross-communication between the Government's agencies would end up in bureaucratic loopholes. We all know that prevention is better than cure. But it has been observed that every actor involved combating TBML focus on after-effect rather than preventing the financial crime like money laundering.

With the rise of artificial intelligence, machine learning, and computation power, a financial crime like TBML/ money laundering can be tackled as developed countries put more afford into digitalization. So it is time to shed some light in this area to establish a sustainable digital infrastructure with appropriate policy that may put Bangladesh ahead of other nations. Without robust monitoring, support from bureaucracy, transparency, and a stable political environment, it would be a big challenge to combat Trade-based Money Laundering in Bangladesh.

In the future, we are aiming to develop a comprehensive framework to combat Trade-based Money Laundering with a focus on "Digitization". Technology is the ultimate weapon to combat financial crimes like Trade-based Money Laundering or any financial corruption. 


\section{References}

APGML. Asia Pacific Group of Money Laundering. Retrieved from http://www.apgml.org/members-and-observers/members/details.aspx?m=060e42602ffd-4403-8594-6e4e8dc4b218

Trading Economics. Bangladesh Balance of Trade. Retrieved from https://tradingeconomics.com/bangladesh/balance-of-trade

The Financial Express. Bangladesh prepares to form pacts with 12 nations for retrieving black money. Retrieved from https://thefinancialexpress.com.bd/economy/bangladesh-prepares-to-form-pacts-with12-nations-for-retrieving-black-money-1604151979

The Daily Star. Bangladesh goes up 28 notches. Retrieved from https://www.thedailystar.net/business/bangladesh-goes-28-notches-1452154

New Age. Bangladesh sees huge capital flight. Retrieved from https://www.newagebd.net/article/101223/bangladesh-sees-huge-capital-flight

The Financial Express. Bangladesh's struggles with money laundering. Retrieved from https://www.thedailystar.net/opinion/the-overton-window/news/bangladeshsstruggles-money-laundering-1923629

Basel Institute on Governance. Basel AML Index Report (2018). Retrieved from https://www.baselgovernance.org/sites/default/files/2019-

02/basel_aml_index_10_09_2018.pdf

The Daily Star. BB moves to curb trade-based money laundering. Retrieved from https://www.thedailystar.net/business/news/bb-moves-curb-trade-based-moneylaundering-1839151

Bangladesh Bank. Bangladesh Financial Intelligence Unit. Retrieved from https://www.bb.org.bd/bfiu/

New Age. BFIU issues guidelines to check trade-based money laundering. Retrieved from http://www.newagebd.net/article/93371/bfiu-issues-guidelines-to-check-trade-basedmoney-laundering

Daily Asian Age. BFIU's new strategy to stop money laundering. Retrieved from https://dailyasianage.com/news/209145/bfius-new-strategy-to-stop-money-laundering

The Financial Express. Combating trade-based money laundering. Retrieved from https://thefinancialexpress.com.bd/views/views/combating-trade-based-moneylaundering-1584113091

The Financial Express. Causes and costs of money laundering. Retrieved from 1596036782 https://thefinancialexpress.com.bd/views/causes-and-costs-of-money-laundering-

The Financial Express. Containing trade-based money laundering. Retrieved from https://thefinancialexpress.com.bd/editorial/containing-trade-based-money-

laundering-1559233144

Davidsson, H. (2014). THE PHENOMENON "MONEY LAUNDERING": Whose money is dirty and what are the effects?

BFIU, Bangladesh Bank. Guidelines for Prevention of Trade-Based Money Laundering. Retrieved from

https://www.bb.org.bd/aboutus/regulationguideline/aml/dec112019_guideline_tbml.pdf John A. Cassara, Chip Poncy, "Trade-Based Money Laundering: The Next Frontier in International Money Laundering Enforcement", Oct. 2015.ISBN: 978-1-119-07895-1

The Financial Express. Money laundering -- no decisive move as yet. Retrieved from https://thefinancialexpress.com.bd/views/money-laundering-no-decisive-move-asyet-1593535661 
The Daily Sun. Money Laundering: The Dark Secrets. Retrieved from

https://www.daily-sun.com/post/319989/Money-Laundering:The-Dark-Secrets-The

Financial Express. Money laundering -- the most serious problem the banking industry faces.

Retrieved from

https://thefinancialexpress.com.bd/views/money-laundering-the-most-serious-

problem-banking-industry-faces

The Financial Express. Reining in trade-based money laundering. Retrieved from

https://thefinancialexpress.com.bd/editorial/reining-in-trade-based-money-

laundering-1565885295

The Financial Express. Retrieval of laundered money. Retrieved from https://thefinancialexpress.com.bd/public/index.php/views/retrieval-of-launderedmoney-1580228643

The Financial Express. Phony imports linked to money laundering! Retrieved from https://thefinancialexpress.com.bd/views/phony-imports-linked-to-moneylaundering-1583075370

Criminal Investigation Department (CID). Statistics of controlled \& disposed cases of CID,

January to March 2019. Retrieved from https://cid.gov.bd/site/content_view/Investigation_statistics

The Financial Express. Strategy to curb illegal flight of capital. Retrieved from https://thefinancialexpress.com.bd/views/opinions/strategy-to-curb-illegal-flight-ofcapital-1600876085

Shamsul Huq Zahid (2020), "Phony imports linked to money laundering!", The Financial Express, Published: March 01, 2020. Retrieved from https://thefinancialexpress.com.bd/views/columns/phony-imports-linked-to-moneylaundering-1583075370

The Daily Star. Take money laundering seriously! Retrieved from https://www.thedailystar.net/editorial/take-money-laundering-seriously-1615015

The Daily Star. The hidden dangers of money laundering. Retrieved from https://www.thedailystar.net/opinion/the-overton-window/the-hidden-dangersmoney-laundering-1569517

The Financial Express. TBML: A black hole in international banking. Retrieved from 1580655993 https://thefinancialexpress.com.bd/views/tbml-a-black-hole-in-international-banking-

The Financial Express. Trade mis-invoicing persists in BD: GFI. Retrieved from 1583294525 https://thefinancialexpress.com.bd/trade/trade-misinvoicing-persists-in-bd-gfi-

The Daily Star. Trade based money laundering: A threat to the growth and sustainable development of Bangladesh. Retrieved from https://www.thedailystar.net/opinion/finance-0/news/trade-based-money-laundering1875451

The Daily Star. Trade-based money laundering on the rise. Retrieved from https://www.thedailystar.net/business/trade-based-money-laundering-the-rise1567393

Dhaka Tribune. Trade deficit in last fiscal year doubles. Retrieved from https://www.dhakatribune.com/business/2018/09/06/trade-deficit-in-last-fiscal-yeardoubles 
Dhaka Tribune. Trade deficit in last fiscal year doubles. Retrieved from https://www.dhakatribune.com/business/2018/09/06/trade-deficit-in-last-fiscal-yeardoubles

The Independent. Trade based money laundering: A threat to development. Retrieved from http://theindependentbd.com/printversion/details/113070

Global Financial Integrity. Trade-Related Illicit Financial Flows: Data by Country.

Retrieved from https://gfintegrity.org/data-by-country/

The Daily Star. How can we prevent trade-based money laundering in Bangladesh?

Retrieved from https://www.thedailystar.net/business/news/how-can-we-preventtrade-based-money-laundering-bangladesh-1915269

The Financial Express. When banks run risk of trade-based money laundering. ?

Retrieved from https://www.thefinancialexpress.com.bd/views/views/when-banksrun-risk-of-trade-based-money-laundering-1566224749

Zdanowicz, John (2009). Trade-Based Money Laundering and Terrorist

Financing.Review of Law \& Economics. 5. 3-3. 10.2202/1555-5879.1419. 